\title{
Resenha de Francisco de Sá Noronha (1821-1881): um músico português no espaço atlântico, de Luísa Cymbron (2019)
}

Marcos Holler ${ }^{7}$

Universidade do Estado de Santa Catarina (UDESC) marcosholler@gmail.com 


\section{Resumo}

O texto apresenta uma resenha do livro Francisco de Sá Noronha (1821-1881): um músico português no espaço atlântico (Cesem/Editora Húmus, 2019), de Luísa Cymbron (Universidade Nova de Lisboa - Cesem), sobre o violinista e compositor português nascido em Viana do Castelo em 1820 e falecido no Rio de janeiro em 1881. Como compositor de óperas, operetas e outros gêneros de música vocal e instrumental, Noronha foi atuante em Portugal e no Brasil no século XIX e sua biografia inclui também viagens aos Estados Unidos, Inglaterra e Cuba.

Palavras-chave: Francisco de Sá Noronha. Ópera no Brasil imperial. História da música no Brasil. Compositores portugueses.

\section{Abstract}

The text presents a review of the book Francisco de Sá Noronha (18211881): um músico português no espaço atlântico (Cesem/Editora Húmus, 2019), by Luísa Cymbron (Universidade Nova de Lisboa - Cesem), about the violinist and Portuguese composer born in Viana do Castelo in 1820 and died in Rio de Janeiro in 1881 . As a composer of operas, operetas and other genres of vocal and instrumental music, Noronha was active in Portugal and Brazil in the 19th century, and his biography also includes trips to the United States, England and Cuba.

Keywords: Francisco de Sá Noronha. Opera in imperial Brazil. History of music in Brazil. Portuguese composers.

1 Marcos Holler é bacharel em Cravo, mestre em Artes e doutor em Musicologia pela UNICAMP. Em 2012 realizou estágio pós-doutoral na Universidade Nova de Lisboa e em 2016 atuou como pesquisador visitante na Hochschule Franz-Liszt em Weimar, na Alemanha, como bolsista da Alexander-von-Humboldt-Stiftung e CAPES. Desde 1995 é professor de História da Música na UDESC, onde se dedica à pesquisa na área de musicologia histórica. Entre 2015 e 2019 foi editor da Opus (revista da ANPPOM). É autor do livro Os jesuítas e a música no Brasil colonial, lançado em 2010. ORCID: http://orcid.org/0000-0002-3739-7158. 
O livro Francisco de Sá Noronha (1821-1881): um músico português no espaço atlântico, de Luísa Cymbron (Cesem/Editora Húmus, 2019), com prefácio do musicólogo Rui Vieira Nery, preenche uma lacuna na historiografia da música no Brasil e em Portugal ao lançar luz sobre o violinista e compositor português Francisco de Sá Noronha. A autora Luísa Cymbron é ligada ao Departamento de Ciências Musicais da Universidade Nova de Lisboa, pesquisadora do Cesem (Centro de Estudos de Sociologia e Estética Musical) e membro do Caravelas - Núcleo de Estudos da História da Música Luso-Brasileira.

A extensa obra (420 páginas no total) - nas palavras da autora, sobre "um violinista e compositor cuja vida decorreu entre Portugal e o Brasil num arco de sessenta anos que abrange as décadas centrais do século XIX" (CYMBRON, 2019, p.9) - é baseada em fontes primárias que incluem documentos manuscritos, impressos originais e partituras, a partir de extensa e detalhada pesquisa realizada em acervos portugueses, sobretudo de Lisboa, e brasileiros, como o Arquivo da Sé do Rio de Janeiro e o acervo da Biblioteca Alberto Nepomuceno da UFRJ. O livro traz não somente a transcrição de documentos, como também imagens e partituras integrais.

Francisco de Sá Noronha nasceu em Viana do Castelo (Portugal) em 24 de fevereiro de 1820 em e faleceu no Rio de janeiro em 23 de janeiro de 1881. Além de violinista, destacou-se sobretudo como compositor de óperas e operetas, porém em seu repertório são listados outros gêneros de música vocal e instrumental, como missas, modinhas e obras para violino e piano. Atuou principalmente no Brasil e em Portugal, países em que obteve êxito na época, mas sua biografia inclui também viagens aos Estados Unidos, Inglaterra e Cuba. No Brasil destaca-se sua colaboração com o dramaturgo Artur Azevedo a partir do final da década de 1870, que, logo após a morte de Noronha, deu início a uma campanha para a construção de um mausoléu. Como afirma Cymbron, apesar das partituras preservadas, suas obras ficaram praticamente esquecidas em Portugal e no Brasil, e sua existência é testemunhada apenas por alguns artigos em jornais e revistas, quase todos do norte de Portugal, referências em catálogos de bibliotecas e uma rua na cidade do Porto.

Segundo a autora, a biografia é um gênero secundário e geralmente enquadrado em uma perspectiva de divulgação, sobretudo na musicologia portuguesa, e uma de suas dificuldades foi a de integrar a obra à narrativa biográfica, ou seja, de "poder olhar a atividade musical e a obra através da vida e vice-versa" (CYMBRON, 2019, p.13), objetivo este que é plenamente cumprido no livro, sendo que essa integração pode ser percebida nos próprios títulos dos capítulos, que remetem à obra e às passagens da vida de Francisco de Sá Noronha.

O primeiro capítulo, "'A crude and eccentric genius': traços de uma personalidade e de uma vida", apresenta uma breve descrição de características pessoais do músico e da documentação pessoal preservada após a sua morte. O capítulo inicia-se com a campanha lançada por Artur Azevedo em 1885 para a construção de um mausoléu para os restos mortais de Noronha e a polêmica surgida a partir dela, que, segundo a autora, reflete questões centrais na vida do compositor: 
[...] sua constante relação com Portugal e com o Brasil [...], a situação no Rio dos emigrantes portugueses com profissões literárias e artísticas, o papel da cultura literária como factor de afirmação da colónia portuguesa nessa cidade, as redes de apoio e sociabilidade entre Portugal e Brasil e, finalmente, a repercussão de tudo isso na obra de Noronha. (CYMBRON, 2019, p.28-29).

No mesmo capítulo são apresentados detalhes das características composicionais de Noronha, com transcrições de partituras que pela extensão talvez ficassem melhor nos anexos. O subitem "O puzzle identitário e a procura de uma afirmação" discute as polêmicas sobre os dados biográficos na literatura e documentação, por exemplo, com relação às suas origens, ao nascimento e à filiação de Noronha, e detalhes pessoais, como seu relacionamento com a família e aspectos de seu temperamento.

O capítulo seguinte, "O violinista 'filho da natureza e do sentimento'", descreve a relação de Noronha com o violino sobretudo como intérprete, mas também como compositor de obras para o instrumento. O texto mantém o termo "rabeca" como nos originais da época, por exemplo no título da obra Fantasia para rabeca sem acompanhamento, composta sobre uma melodia de Thalberg, frequentemente mencionada no texto.

O terceiro capítulo, "Compondo para teatro em língua portuguesa", discorre sobre composição de peças para vaudeville, com as quais ele se destacou no Rio de Janeiro no início da década de 1840, mais do que como violinista. O gênero, nas palavras da autora, "partindo da utilização de árias e canções de sucesso, permitia a criação de uma rede de intertextualidades que eram do particular agrado do público" (CYMBRON, 2019, p.149). O texto menciona O baiano na corte, obra escrita em parceria com João Caetano e estreada em 1851 como um exemplo da adequação ao ideal comum no Rio de Janeiro de um processo de "nacionalização teatral", com a introdução na cena carioca de uma comédia de costumes brasileira. Os jornais da época descrevem a obra como "toda a carácter e costumes de nosso país" e destacam a inclusão de um lundu, transcrito integralmente no livro. O capítulo destaca ainda a participação da esposa, a argentina Juana Manso, como escritora de textos em parceria com Noronha. No texto ela é descrita como pioneira destacada do feminismo sul-americano, jornalista, romancista e ativista política. O capítulo encerra-se com a volta do compositor a Portugal, e as obras estreadas no país.

No quarto capítulo, "Portugal visto do Brasil: a criação de uma ópera nacional", a autora discute a possível influência da campanha pela ópera nacional no Brasil na composição de Noronha, embora não haja uma evidência clara de que ele tenha participado do círculo de compositores que buscavam esse ideal. O capítulo inicia-se com uma carta do comerciante e escritor português Reinaldo Carlos Montoro, que vivia no Rio de Janeiro, cumprimentando Noronha pelo aniversário; a autora parte da relação entre o velho e o novo continente no mundo lusófono na carta como um símbolo do que é discutido a seguir. O capítulo é concluído com uma descrição pormenorizada (ocupando um longo trecho, que chama a atenção pela quantidade de detalhes) da ópera Beatriz de Portugal, baseada em Almeida Garret e apresentada no Teatro de São Carlos, em Lisboa.

O quinto capítulo, "O Arco de Sant'Ana e Tagir: nacionalismos, bairrismos, anticle- 
ricalismos e indianismos", aborda a recepção em Lisboa e no Porto às duas óperas. As sinopses das óperas são apresentadas em detalhes. Tagir é ambientada no Brasil à época da fundação de Salvador, envolvendo colonizadores portugueses, jesuítas e indígenas, o que torna difícil não lembrar de Carlos Gomes, sobretudo com Il Guarany, comparação feita pela autora, que afirma que, "se olharmos apenas para as datas de composição e estreia, diríamos que nada liga directamente estas duas obras, encontrando-se supostamente o libreto e a música de Tagir já numa fase avançada de elaboração quando a ópera de Gomes foi ouvida pela primeira vez" (CYMBRON, 2019, p.284). A autora discorre sobre as fontes das duas óperas, com elementos da crítica genética, e apresenta uma análise harmônica com comparações a trechos de óperas de Verdi; a análise é ilustrada com vários exemplos musicais.

O último capítulo, "O cair do pano: cavalgando o sucesso da opereta no Rio de Janeiro", aborda a volta de Noronha ao Rio em 1878 e sua reinserção no cenário musical da então capital, a partir da parceria com o jovem dramaturgo Artur Azevedo, que encontrou em 1879. Segundo a autora, esse encontro, apesar da diferença de idade, teria sido central para que a memória de Noronha fosse preservada; alguns textos de Azevedo sobre Noronha, sobretudo escritos após seu falecimento e publicados em jornais da época, são transcritos no livro.

Além do grande interesse musicológico da obra, destaca-se a fluência do texto, o que torna a leitura bastante agradável, embora algumas partituras talvez ficassem melhor como anexos, por interromperem o texto ao se estenderem por várias páginas. É uma linguagem descontraída e por vezes informal que não desmerece o trabalho, pelo contrário, o torna interessante para um público não acadêmico, embora a profusão de detalhes de algumas informações de interesse musicológico e algumas análises musicais, de grande interesse para o pesquisador ou historiador da música, possam talvez ser mais do que a esperada para público leigo, tornando a leitura um pouco árdua. Apesar da fluência do texto, a obra encerra-se de forma um pouco abrupta, deixando a sensação de que faltaria uma conclusão ou um encerramento mais de acordo com um trabalho de tal extensão.

O mapa das viagens do compositor e a cronologia com as datas relevantes de sua biografia, colocados logo em seguida à introdução, complementam os dados apresentados no livro, porém no mesmo sentido nota-se a ausência de uma lista de obras do compositor, mesmo que simplificada, o que permitiria uma visão mais geral de sua produção.

A necessidade da busca de um maior contato entre a musicologia brasileira e a internacional, sobretudo portuguesa e hispano-americana, já havia sido apontada por musicólogos desde o final do século passado, como, por exemplo, Paulo Castagna em seu artigo "Avanços e perspectivas na musicologia histórica brasileira" (CASTAGNA, 2008, p.51). A questão é retomada no prefácio de Ruy Vieira Nery, que menciona

[...] um constante intercâmbio musical luso-brasileiro que em nada foi interrompido pela independência de 1822 e que deu à vida musical portuguesa deste período uma escala mais ampla além-fronteiras a que a moderna Musicologia lusó- 
fona, de ambos os lados do Atlântico, tampouco tem prestado a devida atenção. (NERY, 2019, p.XII).

O livro de Luísa Cymbron representa uma importante contribuição nesse processo. A autora menciona a globalização como um fator que, além de ter facilitado o processo de pesquisa com a disponibilização on-line de fundos documentais, possibilitou a aproximação entre as musicologias portuguesa e brasileira (CYMBRON, 2019, p.15). Um ponto a ser discordado neste trecho é a afirmação de que a musicologia seria "centrada em grande parte do estudo do período colonial e do primeiro Império". Um levantamento na literatura da área, em publicações como livros e periódicos, em trabalhos apresentados em eventos científicos e em pesquisas em âmbito acadêmico como dissertações e teses, mostra uma realidade diferente.

Resta-nos esperar que sejam mais frequentes as pesquisas com a excelência do trabalho de Cymbron, sobretudo levando-se em conta a sobreposição das histórias de Brasil e Portugal por alguns séculos. Romper essa dicotomia na historiografia da música dos dois países é mais do que urgente e necessário.

\section{Referências}

CASTAGNA, Paulo Augusto. Avanços e perspectivas na musicologia histórica brasileira. Revista do Conservatório de Música da UFPel, v. 1, p. 32-57, 2008.

CYMBRON, Luísa. Francisco de Sá Noronha (1821-1881): um músico português no espaço atlântico. Lisboa: Cesem/Ed. Húmus, 2019.

NERY, Rui Vieira. Prefácio. In: CYMBRON, Luísa. Francisco de Sá Noronha (1821-1881): um músico português no espaço atlântico. Lisboa: Cesem/Ed. Húmus, 2019. p. III-XIX. 